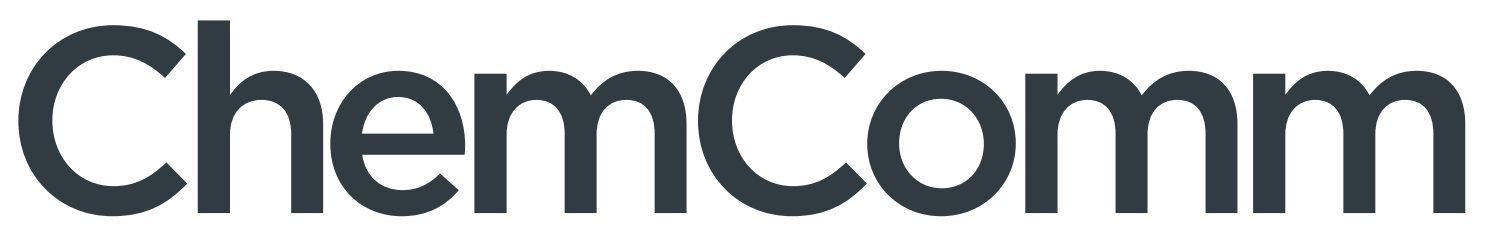

Chemical Communications

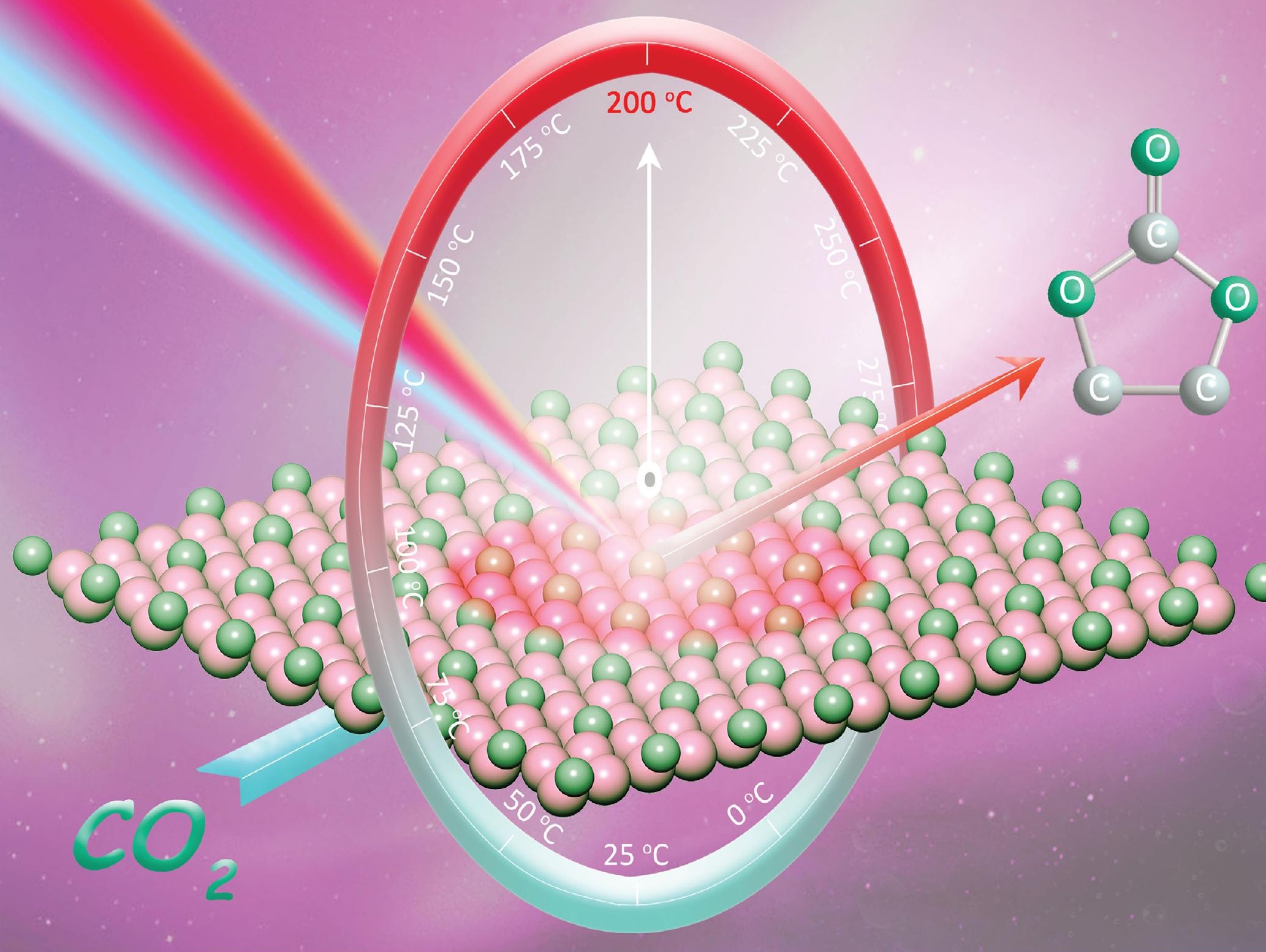

ISSN 1359-7345 
Check for updates

Cite this: Chem. Commun., 2020, 56,7849

Received 11th February 2020

Accepted 4th March 2020

DOI: $10.1039 / \mathrm{d} 0 \mathrm{cc} 01091$

rsc.li/chemcomm

\section{Flower-like cobalt carbide for efficient carbon dioxide conversion $\dagger$}

\author{
Qing Guo, $\ddagger^{\mathrm{ab}}$ Shu-Guang Xia, † $^{\mathrm{ab}}$ Xu-Bing Li, (D)*ab Yang Wang, ${ }^{\mathrm{ab}}$ Fei Liang, (D) bc \\ Zhe-Shuai Lin, (D) bc Chen-Ho Tung (iD ab and Li-Zhu Wu (D) *ab
}

\begin{abstract}
Catalytic conversion of carbon dioxide $\left(\mathrm{CO}_{2}\right)$ to value-added chemicals under mild conditions is highly desired, albeit with significant challenges. Here, in terms of exposure of abundant active sites and excellent photo-to-thermal conversion properties, flower-like $\mathrm{CO}_{2} \mathrm{C}$ has been firstly used for effectively catalysing the cycloaddition of $\mathrm{CO}_{2}$ with epoxides to produce cyclic carbonates with yields of up to 95\% under solar light. Density functional theory (DFT) calculations reveal that Lewis acid sites of the surface Co atoms can activate both $\mathrm{CO}_{2}$ and epoxide, thus opening up the possibility of a $\mathrm{CO}_{2}$-epoxide cycloaddition reaction.
\end{abstract}

The increasing atmospheric concentration of carbon dioxide $\left(\mathrm{CO}_{2}\right)$, which is regarded as the main greenhouse gas, has caused serious environmental concerns (e.g., global warming, abnormal climate change and sea level rise). ${ }^{1-4}$ To address the anthropogenic $\mathrm{CO}_{2}$ emission issues, ${ }^{5-11}$ the approaches of physical $\mathrm{CO}_{2}$ capture and storage, ${ }^{12,13}$ and chemical conversion of $\mathrm{CO}_{2}$ into usable fuels and/or value-added chemicals ${ }^{14,15}$ have been widely investigated. From a chemical point of view, cycloaddition of $\mathrm{CO}_{2}$ with epoxides represents one of the most promising strategies to generate valuable chemicals. ${ }^{16-18}$ By using $\mathrm{CO}_{2}$ as the renewable and nontoxic one-carbon $\left(\mathrm{C}_{1}\right)$ feedstock, ${ }^{19}$ cyclic carbonates are produced with $100 \%$ atom-economy efficiency. ${ }^{20}$ Cyclic carbonates can be directly employed in industry as solvents or intermediates, such as carbamates, ${ }^{21}$ polycarbonates $^{22}$ and spiro compounds. ${ }^{23}$ Numerous advances in homogeneous (e.g., Co, ${ }^{24,25} \mathrm{Ni},{ }^{26} \mathrm{Al}^{27}$ and Cu-based ${ }^{28}$ monometallic or bimetallic complexes) and heterogeneous (e.g., metal-organic-frameworks (MOFs), ${ }^{29-31}$ mesoporous

\footnotetext{
${ }^{a}$ Key Laboratory of Photochemical Conversion and Optoelectronic Materials, Technical Institute of Physics and Chemistry, Chinese Academy of Sciences, Beijing 100190, P. R. China.E-mail: lixubing@mail.ipc.ac.cn,lzwu@mail.ipc.ac.cn

${ }^{b}$ School of Future Technology, University of Chinese Academy of Sciences, Beijing 100049, P. R. China

${ }^{c}$ Key Laboratory of Functional Crystals and Laser Technology, Technical Institute of Physics and Chemistry, Chinese Academy of Sciences, Beijing 100190, P. R. China $\dagger$ Electronic supplementary information (ESI) available: Experimental details. See DOI: $10.1039 / \mathrm{d} 0 \mathrm{cc} 01091 \mathrm{j}$

\$ These authors contributed equally to this work.
}

polymers, ${ }^{32}$ and zeolites ${ }^{33}$ ) catalysts have been made for the cycloaddition of $\mathrm{CO}_{2}$ with epoxides. However, most of the stateof-the-art catalysts can work fairly well to yield cyclic carbonates only at an elevated temperature, thus leading to an increase of the energy cost.

Transition-metal carbides (TMCs) show great potential in the field of catalysis owing to their outstanding electronic conductivity, good chemical stability, abundant surface active sites and high photo-to-thermal conversion efficiency. ${ }^{34-36}$ Cobalt carbide $\left(\mathrm{Co}_{2} \mathrm{C}\right)$, for example, has been demonstrated to be an effective catalyst in various transformations (e.g., hydrogen evolution and Fischer-Tropsch synthesis). ${ }^{37,38}$ However, the application of cobalt carbide in cycloaddition of $\mathrm{CO}_{2}$ with epoxides is still elusive. Considering these attributes, we are inspired to explore $\mathrm{Co}_{2} \mathrm{C}$ as a novel catalyst for cycloaddition of $\mathrm{CO}_{2}$ with epoxides by using solar energy to replace external thermal energy input for following reasons: (i) the high specific surface area and tuneable chemical composition provide abundant surface active sites to activate $\mathrm{CO}_{2}$ and/or epoxides; (ii) the effective $\mathrm{CO}_{2}$ adsorption ability on TMCs favours the very first step of $\mathrm{CO}_{2}$ conversion; ${ }^{39}$ (iii) the huge amount of heat released during the excellent photo-to-thermal conversion process would promote the endothermic reaction (high $\mathrm{C}=\mathrm{O}$ bond energy of $750 \mathrm{~kJ} \mathrm{~mol}^{-1}$ ); ${ }^{40}$ and (iv) the feasible separation and reusability of the heterogeneous catalysts is beneficial for large-scale applications. ${ }^{41}$ To our delight, flower-like $\mathrm{Co}_{2} \mathrm{C}$ facilitates the catalysis of $\mathrm{CO}_{2}$-epoxide cycloaddition with yields of up to $\sim 95 \%$ under visible light (Scheme 1), showing the first example of using TMCs for photothermal-driven $\mathrm{CO}_{2}$ conversion.

Flower-like $\mathrm{Co}_{2} \mathrm{C}$ was synthesized through a modified method of solution pyrolysis at high temperature (Fig. 1a), ${ }^{42-44}$ see experimental details in the ESI. $\dagger$ Scanning electron microscopy (SEM) and transmission electron microscopy (TEM) clearly showed the flower-like morphology of the synthesized material (Fig. 1b and c). The average diameter of the nanoflowers was determined to be $\sim 500 \mathrm{~nm}$ by TEM characterization (Fig. 1c). The nearly apparent nanosheet on the outside of the nanoflowers indicated that the obtained nanoflower was a result of self-assembly of 


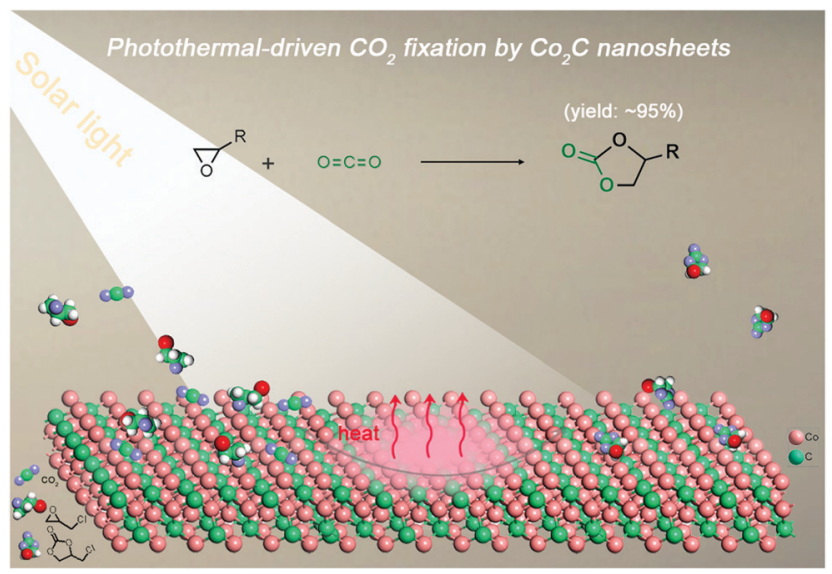

Scheme 1 Illustration of the photothermal-driven cycloaddition of $\mathrm{CO}_{2}$ with epoxides catalyzed by $\mathrm{CO}_{2} \mathrm{C}$ nanosheets of the nanoflower.
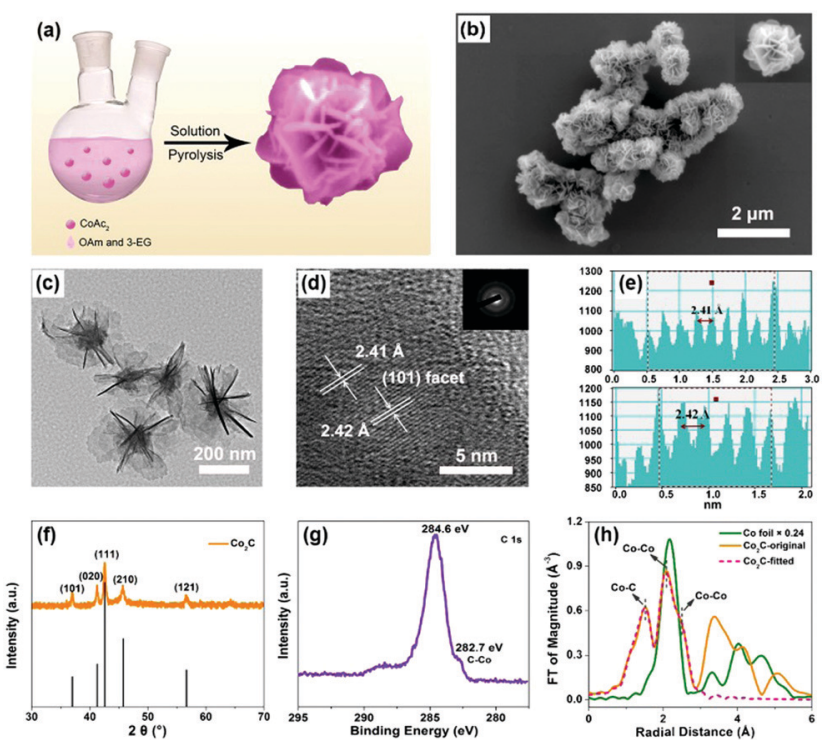

Fig. 1 (a) Synthetic process of flower-like $\mathrm{CO}_{2} \mathrm{C}$. (b) SEM image (the inset panel is the high-resolution SEM image) and (c) TEM image of $\mathrm{CO}_{2} \mathrm{C}$ nanoflowers. (d) High-resolution TEM image of $\mathrm{CO}_{2} \mathrm{C}$ (the inset panel is the corresponding SAED pattern). (e) The corresponding lattice distances of the exposed (101) plane of $\mathrm{CO}_{2} \mathrm{C}$. (f) XRD pattern and (g) $\mathrm{C}$ 1s XPS spectrum of $\mathrm{CO}_{2} \mathrm{C}$ nanoflowers. (h) Magnitude of $k^{2}$-weighted Fourier transform of the Co K-edge EXAFS spectra of Co foil and the obtained $\mathrm{CO}_{2} \mathrm{C}$ nanoflowers with corresponding curve-fitting results.

individual nanosheets. The thickness of individual nanosheet was determined to be $\sim 2.4 \mathrm{~nm}$ by atomic force microscopy (AFM) (Fig. S1, ESI $\dagger$ ). In the high-resolution TEM image, a lattice distance of $\sim 2.41 \AA$ was observed, indicating the exposure of the (101) facet of $\mathrm{Co}_{2} \mathrm{C}$ (Fig. 1d and e). Moreover, selective area electron diffraction (SAED) patterns in Fig. 1d confirmed the polycrystalline nature of the synthesized materials. In addition, elemental mapping analysis indicated the coexistence of $\mathrm{Co}, \mathrm{C}$ and $\mathrm{O}$ elements (Fig. S2, ESI $\dagger$ ), which matched well with the X-ray photoelectron spectroscopy (XPS) results (see below).
The powder X-ray diffraction (XRD) (Fig. 1f) pattern of the as-prepared sample was in good agreement with the standard pattern of $\mathrm{Co}_{2} \mathrm{C}$ (Joint Committee on Powder Diffraction Standards (JCPDS) Powder Diffraction File (PDF) No. 65-1457), ${ }^{42}$ indicating the successful formation of $\mathrm{Co}_{2} \mathrm{C}$. The peaks at 1630, 1420 and $1050 \mathrm{~cm}^{-1}$ corresponding to $\mathrm{C}=\mathrm{C}, \mathrm{C}-\mathrm{H}$, and $\mathrm{C}-\mathrm{N}$ bonds, respectively, in the Fourier transform infrared (FTIR) spectra (Fig. S3, ESI $\dagger$ ) almost disappeared after calcination, suggesting the removal of surface organic ligands. Full XPS survey confirmed the coexistence of $\mathrm{Co}, \mathrm{C}$ and $\mathrm{O}$ elements in the obtained sample (Fig. S4, ESI $\dagger$ ). High-resolution XPS spectra of C 1s (Fig. 1g) and Co 2p (Fig. S5, ESI $\dagger$ ) show the characteristic peaks of carbide and carbidic Co at 282.7 and $778.1 \mathrm{eV},{ }^{36,45,46}$ respectively. Combined with the peak at $531.6 \mathrm{eV}$ in the O 1s XPS spectrum (Fig. S6, ESI $\dagger$ ), the peak at $781.0 \mathrm{eV}$ in the Co 2p XPS spectrum was attributed to the $\mathrm{Co}(\mathrm{OH})_{2}$ species formed in the process of $\mathrm{Co}_{2} \mathrm{C}$ preparation, proving the fact that solution pyrolysis under high temperature inevitably leads to the formation of trace amounts of the hydroxide impurity. ${ }^{46,47}$ Fig. $1 \mathrm{~h}$ shows the X-ray absorption spectra (XAS) of the obtained sample. The Co K-edge extended X-ray absorption fine structure (EXAFS) of the synthesized sample exhibits two peaks in the $R$-space, which could be assigned to the first $\mathrm{Co}-\mathrm{C}$ shell (1.89 $\AA$ ) and the second Co-Co shell $(2.54 \AA)$ of $\mathrm{Co}_{2} \mathrm{C}$, see the fitting details in Table S1, ESI. $\dagger$

Then, photo-to-thermal conversion effects of $\mathrm{Co}_{2} \mathrm{C}$ nanoflowers were experimentally examined. UV-vis-NIR diffuse reflectance spectroscopy (DRS) measurement indicated that the synthesized $\mathrm{Co}_{2} \mathrm{C}$ nanoflowers showed strong absorption in the range of 300 to $1200 \mathrm{~nm}$ (Fig. S7, ESI $\dagger$ ), directly confirming its excellent lightharvesting properties. When the water suspension of $\mathrm{Co}_{2} \mathrm{C}$ nanoflowers $\left(0.6 \mathrm{mg} \mathrm{mL}{ }^{-1}\right)$ was exposed to a $635 \mathrm{~nm}$ laser at varied power densities $\left(0.1,0.5,1.0\right.$ and $\left.2.0 \mathrm{~W} \mathrm{~cm}^{-2}\right)$, the solution displayed apparent temperature elevation (Fig. 2a). For instance, under $635 \mathrm{~nm}$ laser irradiation $\left(0.5 \mathrm{~W} \mathrm{~cm}^{-2}\right)$, the temperature of the $\mathrm{Co}_{2} \mathrm{C}$ nanoflowers water suspension reached $42.8{ }^{\circ} \mathrm{C}$ in 13 minutes, while the temperature of pure water only increased to $24{ }^{\circ} \mathrm{C}$ under the same conditions (Fig. S8, ESI $\dagger$ ). Huge amount of heat released from $\mathrm{Co}_{2} \mathrm{C}$ nanoflowers was also monitored by an IR camera in the solid state. As shown in the inset panel of Fig. 2b, the local temperature of the powder $\mathrm{Co}_{2} \mathrm{C}$ sample quickly increased to $116.8{ }^{\circ} \mathrm{C}$ upon exposure to a $635 \mathrm{~nm}$ laser $\left(0.5 \mathrm{~W} \mathrm{~cm}^{-2}\right)$ for $4.0 \mathrm{~min}$, further confirming the in situ conversion of solar light into heat.

On the basis of the time constant for heat transfer and the maximal steady-state temperature, photo-to-thermal conversion efficiency $(\eta)$, regarded as a major parameter in evaluating the performance in converting light to heat of a given material, ${ }^{48}$ of the flower-like $\mathrm{Co}_{2} \mathrm{C}$ was calculated to be as high as $\sim 63.1 \%$ at $635 \mathrm{~nm}$ (Fig. 2b and c, see details in the ESI $\dagger$ ). The exceptional photo-to-thermal conversion performance of $\mathrm{Co}_{2} \mathrm{C}$ nanoflowers obtained here was comparable with those of the reported materials (Table S2, ESI $\dagger$ ). To further evaluate its photothermal stability, temperature variations of $\mathrm{Co}_{2} \mathrm{C}$ nanoflowers suspension were recorded under light irradiation (laser on) followed by natural cooling to room temperature (laser off). As shown in Fig. 2d, 

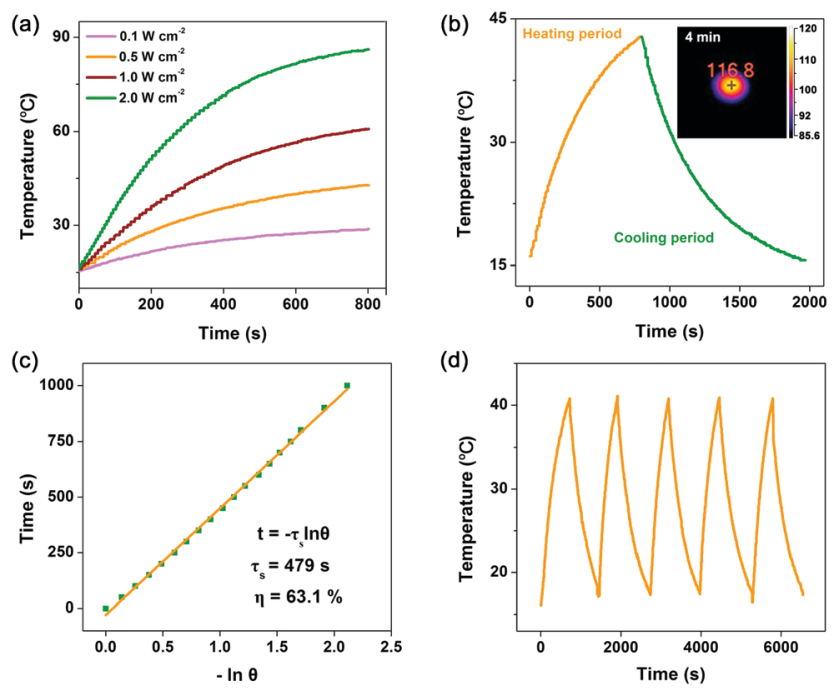

Fig. 2 (a) Photothermal heating curves of $\mathrm{CO}_{2} \mathrm{C}$ nanoflowers dispersed in water under $635 \mathrm{~nm}$ laser irradiation at varied power densities $(0.1,0.5,1.0$ and $2.0 \mathrm{~W} \mathrm{~cm}^{-2}$ ). (b) Photothermal effect of $\mathrm{CO}_{2} \mathrm{C}$ aqueous dispersion under $635 \mathrm{~nm}$ laser irradiation $\left(0.5 \mathrm{~W} \mathrm{~cm}^{-2}\right)$ and the cooling process after laser off. The inset panel in (b) is the IR image of $\mathrm{CO}_{2} \mathrm{C}$ powder under $635 \mathrm{~nm}$ laser irradiation $\left(0.5 \mathrm{~W} \mathrm{~cm}^{-2}\right)$ for $4.0 \mathrm{~min}$. (c) The corresponding time constant $\left(\tau_{\mathrm{s}}\right)$ for the heat transfer from the system determined by applying the linear time data from cooling period. (d) Recycling-heating curves of the $\mathrm{CO}_{2} \mathrm{C}$ aqueous suspension with $635 \mathrm{~nm}$ laser irradiation at $0.5 \mathrm{~W} \mathrm{~cm}^{-2}$ for five laser on/off cycles.

negligible changes in temperature elevation were observed during 5 cycles, which highlighted the potential application of $\mathrm{Co}_{2} \mathrm{C}$ nanoflowers as durable photothermal materials.

To investigate the catalytic performance of $\mathrm{Co}_{2} \mathrm{C}$ nanoflowers, 3-chloropropylene oxide was chosen as the model substrate under visible light (Table 1). A water/fan-cooling system was employed to maintain the outside temperature of the reactor at room temperature, see experimental details in the ESI. $\dagger$ Increase of $\mathrm{Co}_{2} \mathrm{C}$ nanoflowers from 0 to $25 \mathrm{mg}$ obviously improved the yields up to $\sim 93.5 \%$ (entries 1-4; Table 1). Control experiments showed that all components were essential for the conversion. Trace or negligible amount of the product was detected without light, tetrabutylammonium bromide (TBAB) or $\mathrm{CO}_{2}$ (entries 5-7; Table 1). When tetrabutylammonium chloride (TBAC) was employed as the co-catalyst, a significantly declined yield of $\sim 27 \%$ was observed (entry 8; Table 1 ). This result showed that easier dissociation and stronger nucleophilicity of $\mathrm{Br}^{-}$compared to $\mathrm{Cl}^{-}$dramatically benefited the ring-opening reaction of epoxides. ${ }^{29}$ To verify the photothermal effects of $\mathrm{Co}_{2} \mathrm{C}$ nanoflowers, we monitored the temperature variation of the reaction solution by using a thermometer. Upon light irradiation, the temperature of the solution was significantly elevated to $\sim 60{ }^{\circ} \mathrm{C}$ in a period of $35 \mathrm{~min}$ (Fig. S9, ESI $\dagger$ ), indicating the conversion of light into heat. Moreover, very similar yields were observed under either visible-light irradiation or external heating $\left(60{ }^{\circ} \mathrm{C}\right)$, implying that the photothermal effects could promote the cycloaddition reaction between $\mathrm{CO}_{2}$ and epoxide (Fig. S10, ESI $\dagger$ ).

Furthermore, the obtained $\mathrm{Co}_{2} \mathrm{C}$ sample was treated with hydrochloric acid $\left(\mathrm{HCl} ; 6 \mathrm{~mol} \mathrm{~L}^{-1}\right)$ to exclude the contribution
Table 1 Optimization of the reaction conditions ${ }^{a}$

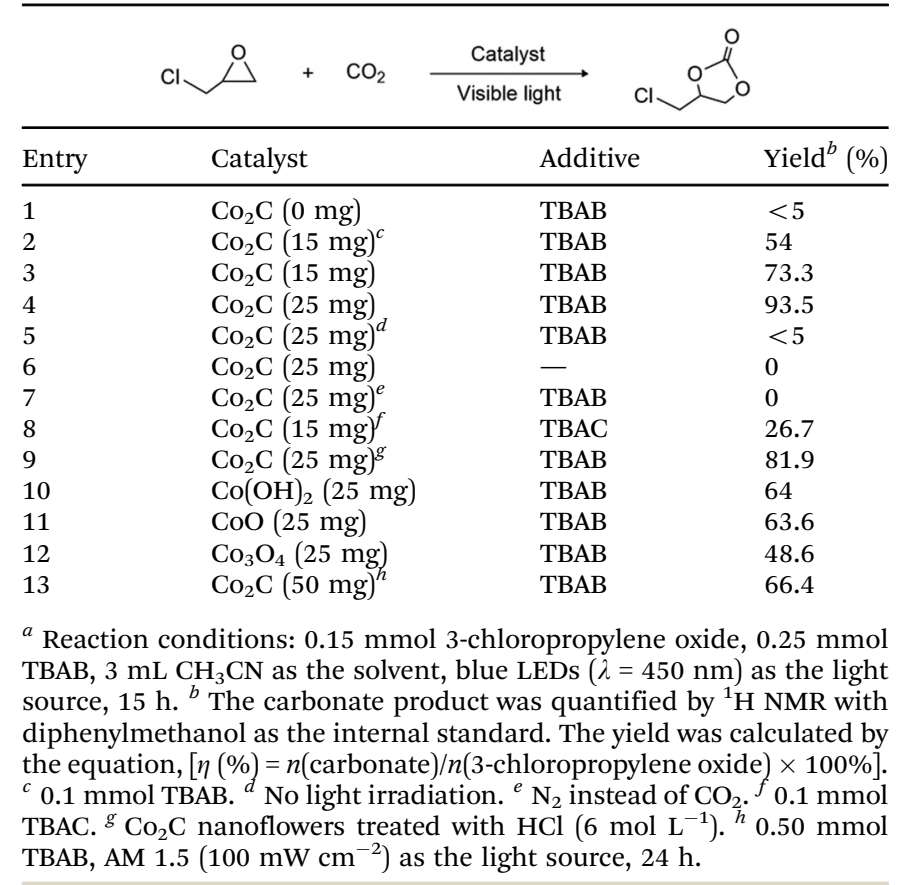

of trace amounts of cobalt hydroxide (i.e., $\mathrm{Co}(\mathrm{OH})_{2}$ ) and/or cobalt oxide (i.e., $\mathrm{CoO}$ and $\mathrm{Co}_{3} \mathrm{O}_{4}$ ) on the surface of $\mathrm{Co}_{2} \mathrm{C}$ nanoflowers in $\mathrm{CO}_{2}$ fixation. After treating the sample with $\mathrm{HCl}$, the slightly declined yield of the target product was still much higher than those of pure $\mathrm{Co}(\mathrm{OH})_{2}, \mathrm{CoO}$, or $\mathrm{Co}_{3} \mathrm{O}_{4}$ under the same conditions (entries 9-12; Table 1). These results confirmed that $\mathrm{Co}_{2} \mathrm{C}$, but not the hydroxide or oxide impurities, served as the real active sites for $\mathrm{CO}_{2}$ fixation. More importantly, the $\mathrm{Co}_{2} \mathrm{C}$ catalysed cycloaddition reaction of $\mathrm{CO}_{2}$ and epoxides with electron-donating/withdrawing groups could also give rise to products in good to excellent yields ( 95\%) (Table S3, ESI $\dagger$ ). Even under AM1.5 irradiation (entry 13; Table 1), this reaction proceeded with good yields. The activity was well preserved after three-time recycling (Fig. S11, ESI $\dagger$ ), indicating the potential use of sunlight as the energy source for enhanced photothermal catalysis.

Based on the above experimental results, a plausible mechanism of the $\mathrm{Co}_{2} \mathrm{C}$ nanoflowers catalysed $\mathrm{CO}_{2}$-epoxide cycloaddition reaction is proposed (Fig. 3). Epoxide molecules adsorb on the surface exposed Co sites via Co-O interaction with an adsorption energy of $-0.53 \mathrm{eV}$ (Fig. S12a, see details of density functional theory (DFT) calculations in the ESI $\dagger$ ), thereby

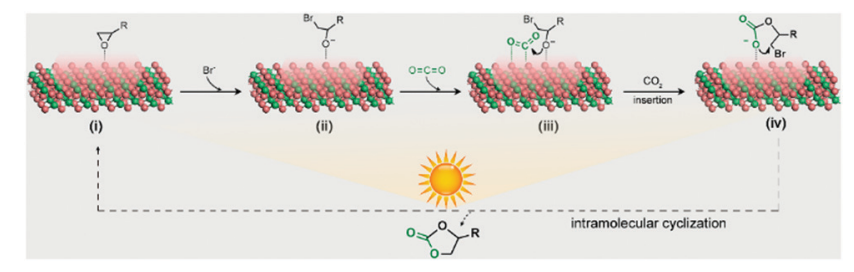

Fig. 3 The proposed mechanism of $\mathrm{CO}_{2} \mathrm{C}$ catalysed $\mathrm{CO}_{2}$ cycloaddition with epoxides under light irradiation. 
leading to the elongation of $\mathrm{C}-\mathrm{O}$ bond from 1.956 to $2.086 \AA$. Then, the nucleophilic $\mathrm{Br}^{-}$ion attacks the adsorbed epoxide at the less hindered carbon atom to generate the metal alkoxide intermediate via the ring-opening reaction. At the same time, $\mathrm{CO}_{2}$ adsorbs on the surface Co atom to give a bent molecular configuration (O1-C-O2 angle $146.99^{\circ}$ ) with a concerted interaction of $\mathrm{C}-\mathrm{Co}$ and $\mathrm{O}-\mathrm{Co}$ coordination (Fig. S12b, ESI $\dagger$ ). With the aid of photothermal $\mathrm{Co}_{2} \mathrm{C}$ nanoflowers, the oxygen anion of the alkoxide intermediate combines with the adjacent highly activated $\mathrm{CO}_{2}$ molecules to yield the cyclic carbonate product, which is eventually released into the solvent to regenerate the catalyst. As a huge amount of heat is released due to the excellent photo-to-thermal conversion effects of $\mathrm{Co}_{2} \mathrm{C}$, the endothermic $\mathrm{CO}_{2}$ cycloaddition reaction proceeds with high yields, which is comparable with the reported results (Table S4, ESI $\dagger$ ).

In summary, an efficient $\mathrm{CO}_{2}$ cycloaddition reaction with epoxides is achieved on low-priced photothermal catalyst of $\mathrm{Co}_{2} \mathrm{C}$ nanoflowers. The yield of cyclic carbonates is up to $\sim 95 \%$ with visible-light irradiation, owing to the excellent photothermal effects of $\mathrm{Co}_{2} \mathrm{C}$ nanoflowers in converting light to heat. Besides, the high specific area as well as efficient $\mathrm{CO}_{2}$ adsorption on the exposed Co atoms of the catalysts can simultaneously activate the adsorbed $\mathrm{CO}_{2}$ and epoxides, thus promoting the $\mathrm{CO}_{2}$ fixation reaction. This work provides new insights into the utilization of TMCs in the field of advanced photothermal-driven catalysis. Moreover, the influence of the morphology, size and thickness of TMCs on the catalytic performance will be further investigated by us.

We are grateful for financial support from the National Key Research and Development Program of China (2017YFA0206903), the National Science Foundation of China (21861132004 and 21971251), the Strategic Priority Research Program of the Chinese Academy of Science (XDB17000000), the Key Research Program of Frontier Science of the Chinese Academy of Sciences (QYZDY-SSWJSC029), the Youth Innovation Promotion Association of Chinese Academy of Sciences (2018031) and the K. C. Wong Education Foundation. We especially thank the Beijing Synchrotron Radiation Facility (BSRF, Beamline 1W2B) for X-ray absorption measurements. We thank Prof. Jiechao Ge and Dr. Qingyan Jia at the Technical Institute of Physics and Chemistry for photothermal-conversion measurements.

\section{Conflicts of interest}

There are no conflicts to declare.

\section{Notes and references}

1 H.-L. Wu, X.-B. Li, C.-H. Tung and L.-Z. Wu, Adv. Mater., 2019, 31, 1900709.

2 X. Jiao, Z. Chen, X. Li, Y. Sun, S. Gao, W. Yan, C. Wang, Q. Zhang, Y. Lin, Y. Luo and Y. Xie, J. Am. Chem. Soc., 2017, 139, 7586-7594.

3 S. C. Peter, ACS Energy Lett., 2018, 3, 1557-1561.

4 J. Ran, M. Jaroniec and S.-Z. Qiao, Adv. Mater., 2018, 30, 1704649.

5 Q. Jiang, Z. Chen, J. Tong, M. Yang, Z. Jiang and C. Li, Chem. Commun., 2017, 53, 1188-1191.

6 S. Wang, B. Y. Guan and X. W. D. Lou, J. Am. Chem. Soc., 2018, 140, 5037-5040.

7 Y. Wang, Z. Zhang, L. Zhang, Z. Luo, J. Shen, H. Lin, J. Long, J. C. S. Wu, X. Fu, X. Wang and C. Li, J. Am. Chem. Soc., 2018, 140, 14595-14598.
8 X. Meng, S. Ouyang, T. Kako, P. Li, Q. Yu, T. Wang and J. Ye, Chem. Commun., 2014, 50, 11517-11519.

9 Q. Guo, F. Liang, X.-B. Li, Y.-J. Gao, M.-Y. Huang, Y. Wang, S.-G. Xia, X.-Y. Gao, Q.-C. Gan, Z.-S. Lin, C.-H. Tung and L.-Z. Wu, Chem, 2019, 5, 2605-2616.

10 Y. Bai, J. Zhao, S. Feng, X. Liang and C. Wang, Chem. Commun., 2019, 55, 4651-4654.

11 J. C. Matsubu, V. N. Yang and P. Christopher, J. Am. Chem. Soc., 2015, 137, 3076-3084.

12 D. J. Heldebrant, P. K. Koech, V.-A. Glezakou, R. Rousseau, D. Malhotra and D. C. Cantu, Chem. Rev., 2017, 117, 9594-9624.

13 G. Kupgan, L. J. Abbott, K. E. Hart and C. M. Colina, Chem. Rev., 2018, 118, 5488-5538.

14 X.-B. Li, C.-H. Tung and L.-Z. Wu, Angew. Chem., Int. Ed., 2019, 58, 10804-10811.

15 C. Lu, J. Yang, S. Wei, S. Bi, Y. Xia, M. Chen, Y. Hou, M. Qiu, C. Yuan, Y. Su, F. Zhang, H. Liang and X. Zhuang, Adv. Funct. Mater., 2019, 29, 1806884.

16 F. Liu, K. Huang, Q. Wu and S. Dai, Adv. Mater., 2017, 29, 1700445.

17 M. Ding and H.-L. Jiang, ACS Catal., 2018, 8, 3194-3201.

18 M. Scharfenberg, J. Hilf and H. Frey, Adv. Funct. Mater., 2018, 28, 1704302.

19 T. Sakakura, J.-C. Choi and H. Yasuda, Chem. Rev., 2007, 107, 2365-2387.

20 Y. Fan, M. Tiffner, J. Schörgenhumer, R. Robiette, M. Waser and S. R. Kass, J. Org. Chem., 2018, 83, 9991-10000.

21 R. Zevenhoven, S. Eloneva and S. Teir, Catal. Today, 2006, 115, 73-79.

22 D. J. Darensbourg, Chem. Rev., 2007, 107, 2388-2410.

23 Y.-X. Zhang, L. Guo, Y.-H. Wang, L.-L. Zhu and Z.-I. Chen, Synth. React. Inorg., Met.-Org., Nano-Met. Chem., 2009, 39, 445-448.

24 X.-B. Lu and D. J. Darensbourg, Chem. Soc. Rev., 2012, 41, 1462-1484. 25 X. Jiang, F. Gou, F. Chen and H. Jing, Green Chem., 2016, 18, 3567-3576.

26 J. Honores, D. Quezada, G. Chacón, O. Martínez-Ferraté and M. J. C. L. Isaacs, Catal. Lett., 2019, 149, 1825-1832.

27 C. J. Whiteoak, N. Kielland, V. Laserna, E. C. Escudero-Adán, E. Martin and A. W. Kleij, J. Am. Chem. Soc., 2013, 135, 1228-1231.

28 J. P. Hallett and T. Welton, Chem. Rev., 2011, 111, 3508-3576.

29 Q. Yang, C.-C. Yang, C.-H. Lin and H.-L. Jiang, Angew. Chem., Int. Ed., 2019, 58, 3511-3515.

30 H. He, J. A. Perman, G. Zhu and S. Ma, Small, 2016, 12, 6309-6324.

31 P.-Z. Li, X.-J. Wang, J. Liu, J. S. Lim, R. Zou and Y. A. Zhao, J. Am. Chem. Soc., 2016, 138, 2142-2145.

32 G. Ji, Z. Yang, H. Zhang, Y. Zhao, B. Yu, Z. Ma and Z. Liu, Angew. Chem., Int. Ed., 2016, 55, 9685-9689.

33 D. Liu, G. Li, J. Liu, Y. Wei and H. Guo, ACS Appl. Mater. Interfaces, 2018, 10, 22119-22129.

34 S. Cao, B. Shen, T. Tong, J. Fu and J. Yu, Adv. Funct. Mater., 2018, 28, 1800136.

35 Z. W. Seh, K. D. Fredrickson, B. Anasori, J. Kibsgaard, A. L. Strickler, M. R. Lukatskaya, Y. Gogotsi, T. F. Jaramillo and A. Vojvodic, ACS Energy Lett., 2016, 1, 589-594.

36 R. Zhao, M. Wang, D. Zhao, H. Li, C. Wang and L. Yin, ACS Energy Lett., 2018, 3, 132-140.

37 J. C. Mohandas, M. K. Gnanamani, G. Jacobs, W. Ma, Y. Ji, S. Khalid and B. H. Davis, ACS Catal., 2011, 1, 1581-1588.

38 Q. Guo, F. Liang, X.-Y. Gao, Q.-C. Gan, X.-B. Li, J. Li, Z.-S. Lin, C.-H. Tung and L.-Z. Wu, ACS Catal., 2018, 8, 5890-5895.

39 I. Persson, J. Halim, H. Lind, T. W. Hansen, J. B. Wagner, L. A. Naslund, V. Darakchieva, J. Palisaitis, J. Rosen and P. O. A. Persson, Adv. Mater., 2019, 31, 1805472.

40 J. Wu, Y. Huang, W. Ye and Y. Li, Adv. Sci., 2017, 4, 1700194.

41 J. Peng, X. Chen, W.-J. Ong, X. Zhao and N. Li, Chem, 2019, 5, 18-50.

42 L. Zhong, F. Yu, Y. An, Y. Zhao, Y. Sun, Z. Li, T. Lin, Y. Lin, X. Qi, Y. Dai, L. Gu, J. Hu, S. Jin, Q. Shen and H. Wang, Nature, 2016, 538, 84.

43 Z. J. Huba and E. E. Carpenter, CrystEngComm, 2014, 16, 8000-8007.

44 M. Zamanpour, S. Bennett, P. Taheri, Y. Chen and V. G. Harris, J. Appl. Phys., 2014, 115, 17A747.

45 H. Wang, S. P. Wong, W. Y. Cheung, N. Ke, W. F. Lau, M. F. Chiah and X. X. Zhang, Mater. Sci. Eng., C, 2001, 16, 147-151.

46 S. Li, C. Yang, Z. Yin, H. Yang, Y. Chen, L. Lin, M. Li, W. Li, G. Hu and D. Ma, Nano Res., 2017, 10, 1322-1328.

47 D. Gazzoli, M. Occhiuzzi, A. Cimino, D. Cordischi, G. Minelli and F. Pinzari, J. Chem. Soc., Faraday Trans., 1996, 92, 4567-4574.

48 L. Yuwen, J. Zhou, Y. Zhang, Q. Zhang, J. Shan, Z. Luo, L. Weng, Z. Teng and L. Wang, Nanoscale, 2016, 8, 2720-2726. 